\title{
Políticas públicas y vulnerabilidad socio territorial en Huautla de Jiménez, Oaxaca, México
}

\author{
Lilia V. López $V$. \\ Facultad de Arquitectura, Profesora Investigadora, Cuerpo Académico en Procesos Territoriales, \\ Benemérita Universidad Autónoma de Puebla, Ciudad Universitaria, Boulevard Valsequillo, C.P. \\ 72570 Puebla, México.
}

Autor de correspondencia: variva35@yahoo.com.mx

Fecha de recepción: 26 de octubre 2016 - Fecha de aceptación: 24 de enero 2017

\section{RESUMEN}

Este trabajo aborda el tema de la vulnerabilidad socio territorial generada en el siglo XX y lo que va del siglo XXI en una ciudad indígena mexicana, conocida también porque ahí vivió la chamana Mazateca María Sabina "la Sabia de los hongos". La ciudad está ubicada en las partes altas de las montañas en la Sierra Mazateca. Las interacciones históricas y contemporáneas entre los procesos físicos del medio ambiente y las políticas públicas, sobre todo las indigenistas, coadyuvaron a modificar paulatinamente el contexto físico natural, las formas y expresiones en el patrimonio biocultural. Huautla es un territorio vulnerable en lo socioeconómico y medioambiental presentando altos niveles de marginación, asentamientos humanos sobre áreas susceptibles a deslizamientos de laderas, deforestación y disminución de la capacidad hidrológica de las microcuencas que abastecen de agua a la ciudad. La investigación está basada en la revisión de documentos sobre políticas públicas mexicanas e indigenistas, contrastándolas con las transformaciones ocurridas en el territorio estudiado.

Palabras clave: Vulnerabilidad socio territorial, políticas públicas indigenistas, transformaciones.

\begin{abstract}
This paper addresses the socio-territorial vulnerability generated in the 20th century with continuation in the 21st century in a Mexican indigenous town, known because the Mazatec shaman María Sabina "the Sage of sacred mushrooms" lived there. The town is situated in the higher parts of the mountains in the Sierra Mazatec. The historical and contemporary interactions between the physical environmental processes and the public policies, especially the indigenous, resulted in a continuous modification of the natural physical environment and degradation of the biocultural heritage. Huautla is a territory vulnerable in it socio-economic and medium environmental, presenting high levels of marginalization, human settlements on slopes susceptible to landslides and deforestation leading to a reduction in the water delivery to the city. The research is based on the historical time depth review of Mexican and indigenous public policies, and the confrontation of findings with the transformations that occurred in the studied territory.
\end{abstract}

Keywords: Socio territorial vulnerability, indigenist public policies, transformations.

\section{VULNERABILIDAD Y COMPLEJIDAD}

En el territorio concebido como una construcción social compleja, se dan distintos factores que interactúan de tal manera que existen sectores vulnerables a varios procesos o fenómenos, ya sea de índole económica, política, cultural, medio ambiental, a desastres, etc. En los últimos años y ante la ocurrencia de desastres propiciados por fenómenos naturales, se le ha dado énfasis a la vulnerabilidad asociada a los mismos, sin embargo existen diferentes situaciones que se expresan en el territorio en 
diferentes escalas, a las cuales los seres humanos son vulnerables como lo son: pobreza, discriminación, marginación, exclusión, desigualdad, personas con capacidades diferentes, mal gobierno, violación de los derechos humanos fundamentales, eventos contaminantes o peligrosos emanados de la actividad humana en instalaciones industriales y de las propias actividades urbanas, hambrunas, guerrasconflictos bélicos y raciales; conflictos aislados, inseguridad y violencia (IFRC.ORG, 2014). Las condiciones de vulnerabilidad pueden ser acumulativas, cuando se padece una o más situaciones que se agravan ante las desigualdades materiales profundas en el seno de nuestras sociedades (Beltrão et al., 2014).

La vulnerabilidad socio territorial es producto de procesos interactuantes, construidos socialmente y determinados por las formas en que los distintos actores sociales con intereses contrapuestos han usado y transformado el territorio (Maldonado \& Cóccaro, 2011), en el que se materializan también la apropiación y el despojo avalados o legitimados como acciones de política pública mediante instrumentos técnicos normativos, en cuyo aparato discursivo se plantea la idea de desarrollo social y bienestar en diversos ámbitos: material, económico, cultural, educativo, de salud, por mencionar algunos, bajo supuestos principios éticos de igualdad, equidad y respeto a la diversidad. Desde la década de los años setenta los planteamientos éticos formulados para el marco de las políticas económicas y regionales en América Latina estaban relacionados con la obtención de valores justos: crecimiento, eficiencia, equidad, estabilidad, calidad de vida y participación de los ciudadanos (Cuervo, 2012). Entre los fines u objetivos a lograr, se planteaba la reducción de los desequilibrios y disparidades interregionales, con la intervención del Estado en la economía regional, como en otros aspectos de la vida humana, para tratar de aminorar las disparidades ocasionadas por el mercado, sobre todo si éstas se manifestaban por diferencias de bienestar y por niveles de vida socialmente inaceptables. Con el neoliberalismo, el papel del Estado cambia radicalmente y la combinación con otros procesos interactuantes en diferentes ámbitos han dado como resultado, al menos en México, una realidad expresada en desequilibrios e inequidades que afectan los derechos humanos fundamentales ${ }^{1}$.

Para comprender la vulnerabilidad socio territorial de Huautla de Jiménez, asumimos que se trata de una problemática compleja ante la cual, retomamos en nuestro análisis, la perspectiva de los sistemas complejos (García, 2006; Morin, 2000; López, 2010), los cuales:

a) Son una representación de un recorte de la realidad (el todo está en la parte y la parte en el todo) lo que le confiere el carácter o principio "hologramático"2: de tal manera que el estado de alta marginación de la población, así como las transformaciones socio territoriales, incluido el deterioro del medio físico ambiental, a tal grado de generar zonas de riesgo, son producto de una serie de procesos comunes también en otros asentamientos indígenas en México, con características similares. El estudiar Huautla nos permite entender cuál ha sido el efecto en esos

1 Los desplazamientos internos a causa de la violencia suscitada por el combate al narcotráfico, entre 2006 y 2013 alcanzan los 700,000 habitantes (Salazar, 2015). En 2011, por la violencia que se vive en sus territorios, incluidos los enfrentamientos entre cárteles y fuerzas de seguridad pública, intolerancia religiosa y conflictos políticos, 1,648,387 personas fueron forzados a dejar su lugar de origen (Castro, 2014); México está clasificado como el tercer país a nivel mundial que reportó en 2014 más muertes por conflictos armados, calculadas en 15,000 personas, según el informe emitido por el Instituto Internacional de Estudios Estratégicos (IIES): "se observa un aumento imparable de la intensidad de la violencia y que las oleadas de rudeza sugieren que los mexicanos aún enfrentan amenazas a la seguridad”. El mismo informe añade que la violencia es operada principalmente por parte de las bandas criminales asociadas con el narcotráfico, el 70\% se distribuye en los diez estados situados a lo largo de las principales rutas de tráfico de drogas a los Estados Unidos (La Jornada, 2015). Los desplazados por desastres naturales 2008 y 2013 ascendieron a 2 millones de personas (Castro, 2014). El comisionado de las Naciones Unidas asevera que en "México hay una ola de continuas violaciones de derechos humanos" ante los elevados niveles de inseguridad, las desapariciones y muertes, el acoso a los defensores de los derechos humanos y los periodistas, la violencia contra las mujeres y los abusos contra los migrantes y refugiados que atraviesan el territorio nacional, rumbo a Estados Unidos. "En un país donde el $98 \%$ de los delitos quedan impunes el panorama es desolador ante la situación de millones de personas, pese al progreso de las reformas jurídicas y constitucionales en la materia, mismas que mantienen una brecha para con la situación real que vive la población” (Hussein, 2015).

2 En un holograma, la menor porción contiene la casi totalidad de la información del holograma representado. El holograma trasciende al reduccionismo que no ve más que las partes y al holismo que no ve más que el todo (Morin, 2000). 
otros asentamientos, de las acciones emprendidas por las políticas públicas indigenistas, las destinadas al campo, en este caso al café y sus efectos socio territoriales.

b) Están constituidos por elementos heterogéneos en interacción, sus subsistemas pertenecen a los "dominios materiales" de muy diversas disciplinas: para este caso recurrimos a la biología, la geología, sociología, economía, antropología, historia y las urbanas.

c) Están conformados por diversos procesos que son interdefinibles: no se puede explicar el estado de marginación sin revisar la intervención del Estado, la entrada del café para cultivo nacional, el papel de actores sociales en la generación de desigualdad, las prácticas deteriorantes del medio ambiente en la construcción de la ciudad, que a su vez se ha realizado sobre laderas con pendientes topográficas muy pronunciadas. Estas interacciones han generado una sociedad vulnerable en lo socio económico y en lo físico ante deslizamientos de laderas, contaminación y escasez de agua. También es importante conocer las condiciones de contorno o procesos externos que han generado modificaciones en los internos, como la firma de tratados o convenios internacionales que han afectado al sector agrícola mexicano, $y$, en caso de Huautla, la dinámica en relación al café y su declive.

d) Necesitan de una conciencia sociológica y socio genética: los territorios son construidos por la interacción de actores sociales, son ellos quienes han fundado la ciudad, la han transformado y hoy la viven, disfrutan o padecen y al mismo tiempo la siguen transformando en un proceso evolutivo sin fin, por lo que es fundamental incorporar su sentir y sus saberes en el conocimiento de su territorio, así como sus perspectivas hacia el futuro.

e) Requieren del abordaje desde una posición transdisciplinaria: no se trata de sumar el conocimiento aportado por las disciplinas mencionadas, sino de cómo los fenómenos que aparentemente pertenecen a cada una, van interactuando entre sí.

f) Requieren el reconocimiento de que los efectos o productos y las causas, son en sí mismos productores y causantes de lo que los produce, lo cual les confiere el principio de "recursividad" : en la zona de estudio las transformaciones, urbano territoriales, incluidas las socio culturales se han dado paulatinamente por modelos o referentes externos que son asumidos por la población, que los hacen suyos, como por ejemplo la entrada de materiales contemporáneos con formas edificatorias no propias de la región, que al ser producidas se convierten en un referente para los demás, que también las retoman y modifican a su gusto de manera sucesiva.

g) Imponen el reconocimiento de nociones que son contradictorias y que se excluyen mutuamente como el orden/desorden, riqueza/pobreza, ciudad sociedad/naturaleza, etc., propio del principio "dialógico"4: las dialógicas se han expresado en el caso que nos ocupa con las contradicciones históricas entre latifundistas, acaparadores y pequeños productores que no han facilitado un comercio justo que beneficie a todos; el crecimiento de los asentamientos humanos sobre zonas con riqueza vegetal que constituyen las únicas fuentes de captación de agua para la ciudad indígena; las políticas públicas impuestas en la región vistas desde una lógica reduccionista que ha fomentado el paternalismo y el asistencialismo en vez de generar acciones autogestivas para la producción y desarrollo de economías locales.

La problemática socio territorial de la zona de estudio no es posible concebirla en términos de la complejidad si no se revisan los principales procesos medio ambientales, socio-culturales, de vulnerabilidad y riesgo, que están interactuando como parte de las interrelaciones con la Región Cañada a la que pertenece. Dicho de otra manera, es necesario descubrir la interdefinibilidad de sus componentes, no se puede explicar uno sin explicar los otros (García, 2006).

\footnotetext{
3 "La sociedad es producida por interacciones entre individuos, la sociedad una vez producida retro actúa sobre los individuos y los produce. La idea recursiva trasciende la idea lineal de la causa-efecto, de producto-productor, de estructura-superestructura, porque todo lo que es producido reentra sobre aquello que lo ha producido en un ciclo, que en sí mismo es auto-constituido, auto-organizador y auto-productor" (Morin, 2000).

4 El principio dialógico asocia dos términos a la vez complementarios y antagonistas (Morin, 2000).
} 
Nuestro enfoque para abordar la problemática de la zona de estudio en esa reconstrucción de un trozo de la realidad, igualmente complejo, nos llevó a preguntarnos en su momento ¿cuáles son los problemas que deseamos abordar y cuáles han sido los procesos que los han provocado?, el enlistado es amplio, sin embargo en esta primera aproximación, necesitamos entender el papel que juega en el ámbito de la Región Cañada, Huautla de Jiménez; ¿cómo ha sido su conformación a lo largo de la historia, el nivel de deterioro medio ambiental y el carácter de las políticas públicas?

Para realizar este trabajo partimos del reconocimiento en el sitio de las condiciones de vulnerabilidad socio territorial actuales, mismas que tratamos de explicar a partir de políticas públicas indigenistas y las aplicadas al campo mexicano, en especial las destinadas al café5, para lo cual revisamos documentos (libros, artículos e informes técnicos), que nos permitieran entender de manera general los procesos internos y externos en diferentes escalas territoriales que propiciaron transformaciones en el sitio.

\section{LA IMPORTANCIA DE HUAUTLA DE JIMÉNEZ EN LA REGIÓN CAÑADA Y SU ENTORNO SOCIO ECONÓMICO}

La ciudad indígena ${ }^{6}$ Huautla de Jiménez, por su ubicación geográfica desde la época prehispánica ha fungido como centro concentrador de actividades político administrativas, siendo sede de las instancias de gobierno desde donde se difunden, las políticas públicas, ejerciendo influencia económica, comercial y de servicios en la Sierra Alta Mazateca ${ }^{7}$ (Luna, 2007; Quintanar \& Maldonado, 1999). En Huautla, hasta los primeros años de la década de los años sesenta se concentraba la cosecha de café proveniente del interior de la sierra, la cuál era llevada en acémilas ${ }^{8}$, para de allí transportarla a Teotitlán-Tehuacán y finalmente a Córdoba Veracruz. Antes de la llegada del INMECAFE ${ }^{9} \mathrm{en} 1961$ ya se habían establecido en la localidad los acaparadores del grano, el cual en el período comprendido entre 1875 a 1960 fue la principal fuente de ingresos económicos (Luna, 2007). Con la desaparición de este instituto en $1989^{10}$ se ubicaron en la localidad diversas instituciones federales y estatales concentrándose los programas gubernamentales emanados de las políticas y economía pública para después ser difundidos al resto de la sierra mazateca (H. Ayuntamiento de Huautla de Jiménez, 2012).

Como antecedente de la implementación de políticas públicas federales indigenistas en la región, en 1960 se instala en Huautla el Centro Coordinador Indigenista, dependiente del Instituto Nacional Indigenista (INI) ${ }^{11}$, instancia que tenía como objetivo investigar los problemas de los núcleos indígenas del país; estudiar las medidas de mejoramiento que requerían y emprender obras de mejoramiento, entre otros.

Huautla es conocida por ser el lugar donde habitó "La Mujer del Libro Blanco" o la "Sabia de los hongos", famosa a partir del año 1955 cuando Robert Gordon Wasson cita a María Sabina en tratados médicos y medios de comunicación de circulación nacional e internacional, como la persona que contribuyó con el conocimiento de los hongos para rescatar sus principios activos: "psilocibina" y "psilocina", utilizados por un sector de la ciencia médica en el tratamiento de depresión, trastornos de estrés postraumático y otros padecimientos (Verdugo, 2003).

5 La producción de café en México formó parte importante de la economía del país.

6 Denominada en 1927, es cabecera del municipio del mismo nombre, cuya población indígena aproximadamente alcanza el 90\% (Instituto Nacional de Estadística y Geografía, INEGI, 2010).

7 Sierra Alta Mazateca pertenece a la Mazateca, región donde se ubican pueblos indígenas mazatecos autodenominados "los que trabajamos el monte, humildes, gente de costumbre”, lingüísticamente pertenecen al grupo olmeca-otomangue. Se ubican al noroeste en el estado de Oaxaca.

8 Acémilas: sobre mulas o animales de carga o en las espaldas de un hombre rudo.

9 Instituto Mexicano del Café

${ }^{10}$ Desaparece en el Sexenio del presidente Carlos Salinas de Gortari, cuando se firma el Tratado de Libre Comercio con Norteamérica, ya dentro del esquema neoliberal de la economía.

${ }^{11}$ Hoy denominada Comisión de los Pueblos Indígenas (CDI). 
Tras la difusión de la existencia de estos psicotrópicos utilizados por los chamanes, arribaron a la ciudad indígena, jóvenes europeos, norteamericanos y mexicanos, miembros del movimiento hippie y simpatizantes, lo que molestó a los habitantes ya que se decía que los visitantes sólo los consumían de manera recreativa, sin entender el entorno cultural y de religiosidad de los indígenas frente al Teonanácatl ${ }^{12}$ a quien veneraban como deidad: "Muchos llegaban para quedarse largo tiempo, sin tener a donde vivir, se instalaban en predios y calles en donde hacían sus necesidades, bailaban, dormían y convivían, escandalizando a la comunidad, lo que provocó que se pidiera la intervención de las autoridades mexicanas para expulsarlos" (Fernández, 2011). En 1976 el ejército acordonó la zona y encarceló a todo aquel que tuviera aspecto extravagante, en ese entonces la cultura dominante consideraba droga el consumo de los hongos (Goujon, 2009). La gente de la comunidad refiere que por Huautla, en busca de los alucinógenos, han pasado personajes como Bob Dylan, los Beatles, Jim Morrison y el rey Juan Carlos de España.

Actualmente la localidad es lugar de abastecimiento de productos básicos, está clasificada como una ciudad con nivel de servicios medio con equipamiento en educación (nivel básico y medio superior regional), salud, cultura, comercio, abastos, recreación y deporte, así como un Hospital Regional Rural público, que da servicio a 40 comunidades, provee a la mazateca media y a las planicies de fuerza de trabajo temporal para las plantaciones de café, la industria de la construcción y el servicio doméstico en ciudades como Tuxtepec, Tehuacán, Puebla, Distrito Federal e incluso en los Estados Unidos (Boege, 1992).

Huautla desde el siglo XX ha sido el asentamiento urbano más grande de la región con 6,862 habitantes en 1960, para el año 2010 alcanza los 10,528 de los 30,004 que contiene el municipio (INEGI, 2010), respectivamente representan el 5.14 y $14.99 \%$ de la población de la Región Cañada, conformada por 200,140 habitantes, asentados en 910 localidades de las cuáles en 905 viven menos de 2,500 personas concentrando el $86.24 \%$ de la población total regional. Es la segunda región más importante en habitantes hablantes de lengua indígena, alcanzando el $74 \%$ de su población.

La vulnerabilidad socio económica se expresa en el 97\% de las localidades que en el año 2005 se clasificaron entre muy alta y alta marginación, siendo la Cañada la región del Estado de Oaxaca que reportó mayores porcentajes en: a) personas analfabetas calculadas: $31.7 \%$; b) población sin primaria completa, $27.6 \%$; c) en cuanto a cobertura de servicios se refiere, es la región más atrasada en comparación con el resto del Estado, ocupando el primer lugar en viviendas que no disponen de energía eléctrica ni agua entubada, la segunda en viviendas sin drenaje y la tercera en viviendas con piso de tierra; d) en acceso a la salud, un $43.5 \%$ de su población no es derechohabiente a algún sistema de salud; e) es expulsora de población (H. Ayuntamiento de Huautla de Jiménez, 2012).

En ese contexto una de las principales ramas económicas del municipio de Huautla es la agrícola, misma que ha perdido capacidad para producir alimento, entre otros factores debido a la baja intensidad en la expansión de la agricultura comercial o especializada, los bajos precios que adquirieron los granos básicos y el café, una lenta incorporación de tecnología a las labores agrícolas, aunado a la puesta en marcha de políticas públicas tanto sociales como en el agro mexicano que han contribuido al decaimiento y crisis de este sector en el país. En Huautla de Jiménez esto se expresa con bajo valor agregado; grandes redes de intermediación; falta de infraestructura caminera; altos costos de transporte y acopio; falta de plantas para transformación agroindustrial; y por consecuencia, economía atrasada y empobrecida. Aunado a esto, las redes de acaparamiento del café, al igual que la producción de frutas, puso en desventaja a los productores de la Sierra Mazateca, incluidos los de Huautla, desde principios de siglo. Al finalizar el siglo XX, todas las regiones de Oaxaca presentaban serias concentraciones de población en pobreza, destacando la Cañada y Sierra Norte con los porcentajes más altos (Ruiz \& Campechano, 2006).

En la localidad, el comercio y los servicios constituyen la mayor actividad económica, misma que se ha incrementado de manera importante, en 1960 representaba el 30.04\% de la Población Económicamente Activa PEA local, a inicios del siglo XXI alcanzó el 60.93\%. Una fuente importante de recursos económicos es la migración, por lo que contingentes de población están saliendo definitiva o temporalmente en busca de trabajo e ingresos para su sobrevivencia; actualmente la economía se

12 Nombre del hongo en Náhuatl. 
explica más por los ingresos que se obtienen fuera de la localidad y de los subsidios que aportan los programas gubernamentales y no por lo que ocurre al interior del municipio (Fernández, 2011). Sin embargo, al igual que ocurre en muchas localidades del país, los subsidios económicos provenientes de los programas asistenciales que otorga el gobierno federal no logran generar impulso al desarrollo interno, tampoco la agricultura, el comercio, los servicios, ni los recursos provenientes de los migrantes, se han podido constituir como factores capaces de impulsar el crecimiento económico, colocando a la población en situación de vulnerabilidad socio económica.

La dependencia alimentaria y la falta de medios de producción alternativos a la agricultura, constituye en gran parte la base de la pobreza de Huautla, en el municipio el 82.1\% (21,502) de los habitantes vive en pobreza, de los cuáles el $52.6 \%(13,759)$ padece pobreza extrema, en cuanto a la disponibilidad de servicios básicos en las viviendas el $83.1 \%(21,749)$ carecen de ellas, el $52.3 \%$ $(13,695)$ de la población reportó habitar en viviendas con materiales inadecuados e espacios insuficientes; el 46.9\% $(12,278)$ carecen de servicios de salud y el $38.8 \%(10,169)$ reportan rezago educativo (CONEVAL, 2010).

En la ciudad de Huautla se presentan relaciones sociales de alta desigualdad. Por un lado vive un gran número de profesores que perciben salario fijo, marcando diferencias en el poder adquisitivo en comparación de los pobladores que viven del campo. Por otro lado, existe presencia de una clase empresarial y comercial, altamente depredadora, que saquean madera de los bosques aledaños, y que no contribuyen al desarrollo y bienestar de las comunidades. Estas zonas deforestadas aunadas a las características físicas del suelo, propenso a deslizamientos, generan áreas de peligro, comprometiendo la capacidad hidrológica de las microcuencas (H. Ayuntamiento de Huautla de Jiménez, 2012).

Esta vulnerabilidad es expresión hologramática del entorno socio económico en el que se encuentra la localidad y la Región Cañada, siendo el estado de Oaxaca ${ }^{13}$ una de las entidades históricamente más deprimidas de México, que se ha caracterizado por ser poco dinámica y con baja productividad, ocupa el segundo lugar en cuanto a población viviendo en pobreza y pobreza extrema ${ }^{14}$, con un $66.8 \%$ y $28.3 \%$ respectivamente (Instituto Méxicano de Competitividad, 2014). En este país, en situación de pobreza viven 55.3 millones de mexicanos, alcanzando el $46.2 \%$ del total nacional en el año 2014, de los cuáles, 11.4 millones $(9.5 \%)$ padecen precariedad extrema caracterizada, entre otros, porque no tienen recursos para alimentarse (CONEVAL, 2015). Este fenómeno ha predominado durante los últimos 20 años, en los que, según datos del Banco de México, el ingreso económico de más de 23 millones de mexicanos, al año 2015, es insuficiente para comprar la canasta básica, encontrándose 61.4 millones de habitantes en pobreza moderada.

\section{POLÍTICAS PÚBLICAS, SU IMPACTO EN LA COMUNIDAD}

La evolución ${ }^{15}$ socio territorial de Huautla es resultado de diversos procesos, muchos de ellos resultado de acciones de política pública que a lo largo de la historia han contribuido tanto en la conformación física actual como en las condiciones de marginación de la población. Con la llegada de los españoles se desestabilizó la organización social, económica, administrativa, política y jurídica, así como la ideología cargada de simbolismo, los mazatecos al igual que muchos pueblos, tuvieron que adaptarse a la sujeción extranjera (INI, 1994). Las epidemias, provocadas por enfermedades (viruela y sarampión) traídas por los ibéricos, los maltratos, la mala alimentación y los trabajos pesados, devastaron a la población indígena, reduciéndola a casi el 10\%, sobreviviendo sólo 2,500 individuos al final del siglo XVI, se formó entonces una nueva elite que se dedicó a acaparar el comercio de la zona y a recibir los

13 Se ubica en la porción Suroeste de la República Mexicana, ocupa el 4.8\% de la superficie del país.

${ }^{14}$ La medición de la pobreza en México se realiza de manera oficial, considerando los indicadores arrojados por la Encuesta Nacional de Ingresos y Gastos de los Hogares del Instituto Nacional de Estadística y Geografía (INEGI), en el año 2014, incluyó dos grandes rubros: a) El ingreso de los hogares y b) las carencias sociales en materia de: Educación, Acceso a los servicios de salud, Acceso a la seguridad social, Calidad y espacios de la vivienda, Acceso a servicios básicos en la vivienda, Acceso a la alimentación y Cohesión social.

15 Cuando hablamos de evolución, solo nos estamos refiriendo a cambios y transformaciones. 
tributos y servicios de los pueblos, adaptando el sistema tributario indígena al nuevo régimen socio económico de la Nueva España, la introducción de la religión cristiana significó cambios en las prácticas indígenas (Luna, 2007). La corona impulsó el comercio aprovechando las mismas rutas comerciales prehispánicas, estableciendo un circuito económico, de manera que los pueblos de la parte alta donde se encuentra Huautla, recibían productos de la parte baja que no tenían.

En la región mazateca para 1860, como resultado de la reforma Juarista ${ }^{16}$, las haciendas tomaron auge, sometiendo a los mazatecos a trabajos forzosos, quitándoles sus parcelas a través de múltiples formas de coacción. En la época de la Reforma (1855-1860) desaparecieron los linajes nobles, pero los caciques nativos de las comunidades seguían manteniendo el control de sus territorios, surgieron los sistemas de cargos como consecuencia de una nueva configuración política (Luna, 2007). En el porfiriato ${ }^{17}$ a la Sierra Alta y Media mazateca arribaron latifundistas extranjeros, quienes acapararon las tierras dedicadas a la producción de café (Quintanar \& Maldonado, 1999).

Al inicio del siglo XX ya se había colocado a la cima de la estructura de clases un grupo privilegiado conformado por blancos y mestizos, que controlaban el comercio y contactos con el exterior, mientras la población indígena mantenía una economía de subsistencia subordinada a la economía nacional. Terminado el período revolucionario, los de la parte alta, que corresponden al área de estudio, fueron recuperando sus terrenos mediante la ocupación o comprándolos a los latifundistas, quienes se convirtieron en acaparadores de café. Estos hechos no están aislados de la política regional que se implementa en México en el período de 1885 a 1940, el despojo de tierras y la exclusión de los indígenas durante el siglo XIX se puede explicar, en parte, por una política dirigida hacia la erradicación de los indígenas y así "blanquear" al país, con leyes dirigidas contra las tierras colectivas de las comunidades, mismas que pudieron resistir mediante el sistema de cargos (Korsbaek \& Samano, 2007).

La ley de la Reforma Agraria (1915) forma parte de las acciones pioneras del siglo XX, implementadas por el gobierno posrevolucionario con incidencia en la organización del espacio, significando el principal instrumento de colonización del país. La política indigenista de los años veinte se dirigió a la educación y las misiones culturales, promovidas a través de la Secretaria de Educación Pública bajo la dirección de José Vasconcelos. Durante el período del presidente Lázaro Cárdenas (1934-1940) se voltea la mirada hacia la inclusión del indio en la sociedad mexicana, institucionalizándose el indigenismo en las políticas públicas. En 1940 se inicia, a nivel de la planeación urbano-regional, el período de impacto territorial aislado, que se caracterizó porque el gobierno federal estableció una serie de políticas de carácter esencialmente sectorial dirigidas a estimular la industrialización y el sector agropecuario (López, 1992).

En el marco de la planeación en general y urbano regional, en el país bajo el gobierno de Miguel Alemán (1946-1952) se crean en 1946 las Comisiones de Cuencas Hidrológicas como una estrategia de desarrollo mediante proyectos de aprovechamiento y transformación de los recursos hidráulicos, sin embargo esta estrategia que duró varios lustros no produjo los resultados esperados, ya que en lugar de generar un desarrollo urbano regional menos dispar, impulsó el crecimiento industrial de las principales ciudades de las regiones, a costa de los ecosistemas y recursos locales de los lugares en donde se establecieron las presas hidroeléctricas (López, 1992). La mazateca no fue la excepción, en 1947 se construye la presa Miguel Alemán, inundando las tierras de cuatro municipios, teniendo que reubicar a 22,000 indígenas en ecosistemas distintos de Oaxaca y Veracruz. Décadas más tarde, con los objetivos de ampliar la capacidad instalada de generación de energía eléctrica de la presa Miguel Alemán, evitar las inundaciones de la parte baja del río Papaloapan y crear un distrito de riego, se construye la Presa Cerro de Oro (1972) en el noroeste de Oaxaca, expropiando tierras ejidales y desplazando a 26,000 campesinos, en su mayoría indígenas (Rojo, 2014).

Y aunque estas acciones de política pública federal tuvieron lugar en la zona baja mazateca, los impactos denominados como "cataclismo ambiental y cultural" han afectado a nivel regional y sobre todo al espíritu y destino de los desplazados, a quienes hoy en día no se les ha hecho justicia, colocándolos en situación de pobreza, exclusión y pérdida de sus territorios (INI, 1994). Por si esto no hubiera sido suficiente, en el año de 1997, para aumentar el nivel del agua de las dos presas, se

${ }^{16}$ Leyes que se impulsaron bajo el mandato del presidente Benito Juárez 1857-1872.

17 Se le denomina porfiriato al período presidencial de Porfirio Díaz entre los años 1877 y 1911. 
desplazaron nuevamente a 18,000 indígenas ${ }^{18}$ (García, 1997). La construcción de esta infraestructura hidráulica no benefició a los pueblos mazatecos ya que la energía eléctrica generada proveía principalmente a la ciudad de México, existiendo aún en el año 1990 comunidades que carecían de este servicio.

Retomando el tema indígena en las políticas públicas, durante el siglo XX podemos afirmar que atravesó por varias etapas, siendo significativa la creación, del INI en $1948^{19}$, con la perspectiva de integrar a los indígenas a la cultura nacional, mediante su aculturación a partir de la acción indigenista en las regiones interculturales, también denominadas "regiones refugio", porque de acuerdo a la teoría de Aguirre Beltrán los cultos que iban erradicando los españoles en el proceso de evangelización, obligaban a los indígenas a vivir en lo alto de las sierras para salvar sus prácticas culturales que tanto escandalizaron a los españoles, como el caso del consumo de hongos alucinógenos (Goujon, 2009).

Con la creación del INI se pretendía inducir el cambio cultural de las comunidades y promover el desarrollo e integración en las regiones interculturales a la vida económica, social y política de la nación (CDI, 2012). En Huautla de Jiménez se instala el Centro Coordinador Indigenista (CDI) en 1960, el cuál jugó un papel fundamental en la transformación territorial de la localidad y de la región, durante más de una década contribuyó a la construcción de infraestructura y equipamiento educativo, de salud, sanitarios (letrinas, lavaderos y cajas de agua), de almacenamiento de agua potable, de comunicación con la apertura de brechas y caminos y reconstrucción de los que eran dañados por los derrumbes, a la creación de asociaciones agrícolas y de organizaciones de pequeños productores, otorgó y coadyuvó en servicios educativos y médicos (Incháustegui, 1960-1969).

Otra política pública federal de fuerte impacto regional fue la enfocada a la producción y comercialización del café, incluida la creación del INMECAFE en 1958 y cuya aparición en Huautla se da en 1961. Las políticas públicas nacionalistas en las que el indigenismo estaba institucionalizado, empiezan a decaer en 1982, cuando Miguel de la Madrid al inicio de su periodo presidencial ante la situación económica del país, tras la nacionalización de la banca operada por el presidente saliente, la fuerte devaluación del precio del peso mexicano frente al dólar estadounidense y el ambiente de enfrentamiento entre la iniciativa privada y el gobierno, solicita apoyo económico al Banco Mundial y al Fondo Monetario Internacional, subsumiendo el destino de México a las políticas neoliberales (Korsbaek \& Samano, 2007).

En este modelo el indigenismo, concebido como un proyecto nacional en el que los indígenas eran coparticipes del desarrollo ya no es factible, lo que lleva a la desaparición del INI (2003), para ser sustituido por la Comisión Nacional para el Desarrollo de los Pueblos Indígenas. Institución que paulatinamente ha disminuido sus programas, mismos que al igual que los del INI, por la forma en que fueron y son operados, en la región, no han logrado superar las prácticas paternalistas que impusieron, ni han fomentado prácticas autogestivas para la producción y comercialización de sus productos, que les permitan superar la pobreza (Sánchez, 2013).

\subsection{El café en las políticas públicas}

México es el quinto productor mundial de café, producto que forma parte de la economía desde finales del siglo XVII. La llegada del aromático está vinculada a la disminución de la cosecha brasileña a causa de una plaga en 1888 y al impulso del gobierno de Porfirio Díaz a la inversión extranjera en México. Se trató de las primeras acciones de política pública enfocadas a la producción del café mediante la explotación de los indígenas de las regiones aptas para su cultivo, en beneficio de la iniciativa privada.

A finales del siglo XIX a la región Cañada llegaron los primeros finqueros y las matas de café, su cultivo propició la existencia de grandes haciendas y fincas que utilizaban la fuerza de trabajo indígena,

18 En México los desplazados a causa de la puesta en marcha de acciones de política pública sobre el territorio (presas hidroeléctricas y minas), se consideran movimientos necesarios del "desarrollo", alejando a poblaciones enteras de sus tierras y formas tradicionales de subsistencia, lo que ha implicado llevarlos a condiciones de pobreza. Tan solo para la construcción de presas al iniciar el año 2016, suman aproximadamente 200 mil habitantes desplazados (Gutiérrez, 2016) en su mayoría de comunidades indígenas y campesinas, cuyos territorios sufrieron lo que Boege (2008) denomina "cataclismo biocultural".

19 Sustituyendo al Departamento Autónomo de Asuntos Indígenas creado en 1935. 
las primeras haciendas se construyeron en comunidades cercanas a Huautla. Las acciones de política pública en este sector, entre 1888 y 1988, fueron diseñadas desde la federación para todo el país, confiriéndole al Estado un papel importante en el desarrollo del mismo y en el caso que no ocupa, en la regulación de precios, comercialización y exportación del aromático. Nolasco (1985) señala para ese periodo cinco etapas en las políticas públicas destinadas al café:

1) Penetración del sector privado (1888-1947) estableciendo tres sistemas de relaciones productivas: patrón-peón, acaparador-productores y acaparadores-productores marginales, siendo el de patrón-peón el que se desarrolló con apoyo del Estado, no interfiriendo con el capital extranjero, que operó sin mediación en las fincas. El sistema acaparador-productor marginal persistió donde existían grandes cacicazgos locales y regionales. La inversión extranjera en este sector al año 1942 alcanzaba en México el 60\%, que junto con inversionistas nacionales desarrollaron una fuerte red de compraventa, mientras que los campesinos sólo vendían su producción a patrones locales quienes la comercializaban a patrones regionalescaciques, para ser comprada por intermediarios. En la Cañada la comercialización inicial se realizaba mediante arrieros y acémilas que transportaban el producto al exterior, a cargo de los propios hacendados.

En la mazateca, desde la revolución y hasta la década de los años cincuenta, se construye una larga red, desde los pequeños productores hasta los grandes exportadores, con intermediarios: acaparadores, compradores, ambulantes, arrieros y muleros que, en su mayoría, por no contar con recursos económicos, los obligó a depender del financiamiento de los grandes compradores de Huautla de Jiménez o Teotitlán del Camino (Traffano, 2012).

2) Penetración inicial del sector público en las zonas cafetaleras (1948-1958), mediante la Comisión Nacional del Café que junto con la Unión Nacional Agrícola de Cafetaleros (UNAC), formadas la primera por el gobierno federal y la segunda, por los patrones y acaparadores, tenían como objetivo facilitar la producción y mejorar la comercialización, aprovechando el aumento de los precios del aromático (1947-1948) resultado del déficit de producción en el mercado mundial tras la segunda guerra mundial, impactando positivamente a las exportaciones mexicanas, con lo que se pensó que el café podría representar una fuerte fuente de ingresos para el gobierno mediante impuestos federales. Sin embargo la industria mexicana no tenía la capacidad de producción, lo que motivó la creación de la Comisión Nacional del Café (1949) con el objetivo de lograr que las plantaciones mejoraran, lo que requirió involucrarse directamente en el campo, situación compleja porque existían miles de cafeticultores ubicados en rincones alejados de las vías de comunicación, con predios reducidos, hablantes de más de cien lenguas distintas y culturas diversas, por otro lado las elites de la industria cafetalera con una fuerte red de penetración en el campo, significó una desventaja para la Comisión. Entre 1948 y 1953 las exportaciones se duplicaron de 31,000 a 69,000 toneladas, prevaleciendo la producción concentrada en un reducido número de grandes productores dueños de las fincas (Nolasco, 1985).

La creación del INI (1949), facilita la penetración del sector público en territorios indígenas favoreciendo la implantación del sector privado en el ámbito tradicional del productor indio de café. En la mazateca, la estructura comercial para hacer llegar el café al mercado nacional e internacional, era semejante al de otras regiones indígenas del país, las características físicas, lo accidentado del territorio, la falta de caminos y medios de transporte, así como el volumen de la producción, propiciaron que la mayoría de los pequeños productores dependiera de los compradores ambulantes para la venta del café. En los pequeños poblados mazatecos no había un comprador establecido y donde sí lo había, formaba parte de la estructura piramidal de comercialización, los exportadores eran los más interesados en captar el volumen de la producción indígena, que además por la diferencia de precios, obtenían un margen considerable de ganancia. Los grandes exportadores de la región financiaban a varios comerciantes, que adquirían generalmente el café pergamino de Huautla.

Estos intermediarios compraban el aromático directamente a los productores o a los arrieros, pagando a los pequeños productores sólo la tercera parte del precio. El mecanismo de compras por adelantado a manera de préstamo, no favoreció a los pequeños productores ya que los 
arrieros y los comerciantes adelantaban dinero a los productores por el café a cosechar, el prestamista fijaba el precio futuro por debajo del precio esperado y se le añadía el interés cobrado sobre los préstamos, lo cual depauperaba aún más el precio pagado al pequeño productor (Traffano, 2012).

3) Reorganización de los sectores público y privado (1958-1970) producto de las fluctuaciones en el valor del café, ya que mientras en 1954 el saco alcanzó los 100 dólares, en 1958 se vendía en 68 dólares, provocando conflictos entre ambos sectores por la afectación en las ganancias tanto de exportadores como beneficiarios y productores. Esto, ya que la ganancia de los exportadores dependía del precio en que pudieran colocar el producto y los bajos precios pagados a los productores y beneficiarios (Nolasco, 1985). Los exportadores forman la Asociación Mexicana del Café (AMEC) (1957), permaneciendo los beneficiarios y grandes productores en la UNAC, incorporando a los patrones regionales y a los dueños de los beneficios, dejando fuera a miles de cafeticultores minifundistas. La Comisión Nacional del Café se modifica en octubre de 1957 como resultado de la firma de un acuerdo internacional ${ }^{20}$, con el objetivo de estabilizar el precio del café en el mercado mundial, lo que implicó que el gobierno mexicano se comprometiera a promover su consumo interno, reducir la superficie de producción e incrementar la productividad en zonas cafetaleras.

Para lograr esa tarea se requería estrechar los vínculos con los productores del café, y se crea el INMECAFE (1958), entre cuyos objetivos estaba: la implementación de acciones más amplias en el campo cafetalero, actuar en el mercado para regularlo, mitigar los conflictos entre los exportadores y los beneficiarios-productores. Sin embargo, el papel de mediador se vio obstaculizado por el bajo nivel de operación en el que actuó, tanto por su capacidad financiera como técnica, así como factores políticos de caciquismo.

En Huautla, al igual que en otras regiones, el INMECAFE pretendió transformar las estructuras de comercialización que ponían en desventaja a los productores minifundistas que se encontraban en el último eslabón de la cadena, el instituto, en colaboración con el INI, en 1961 crea una estructura de comercialización paralela para favorecerlos regulando el precio del café, formando en 1962 la primera asociación agrícola local. Esta alianza afectó a los intermediarios y al sistema de dominación caciquil, dando lugar a actos de violencia y enfrentamientos que culminaron con el asesinato del líder Erasto Pineda ${ }^{21}$ en junio de 2016. La producción regional se calculaba entre 60,000 y 120,000 quintales anuales, la oficina de BEMEX ${ }^{22}$ en el segundo año captó un porcentaje considerable de la cosecha, sin haber logrado una cadena de intermediación paralela que compitiera con la estructura comercial tradicional, lo que trajo como consecuencia una fuerte disminución en sus compras. Ante la tendencia en el alza del precio del café, se hubiera esperado que el volumen de compras aumentara, sin embargo, tras el asesinato de Pineda, las presiones y amenazas de los comerciantes sobre los productores, negándoles créditos para su subsistencia anual si no les seguían vendiendo el producto a ellos, provocaron que dejaran de llevar el café a las oficinas de BEMEX, pese a que les pagaba un precio más alto, disminuyendo el grano captado por la institución. Para 1965 el INI había fomentado la creación de dos asociaciones agrícolas locales, una de ellas en Huautla y programaba otras cuatro, para lo cual solicitó al INMECAFE que enviara un ingeniero agrónomo para instalar viveros y renovar las plantaciones. Después de diez años de proporcionar deficiente asistencia técnica y aprovechando su condición de funcionario del gobierno, el ingeniero se convirtió en un miembro de la estructura del poder regional para controlar a las diferentes asociaciones de productores que había promovido el INI (Flores \& León, 1979).

Después de haber participado los primeros años en acciones contra la estructura caciquil, el INI se retiró, dedicándose a las actividades educativas y a la obtención de servicios para los pueblos

20 Convenio de México.

${ }^{21}$ Líder nato que luchaba al lado de los campesinos pequeños productores de café por un mejor precio para el grano.

22 Beneficios Mexicanos, dependiente del INMECAFE. En los primeros cinco años de funcionamiento del centro de compras de BEMEX, el INI y el personal a cargo fueron objeto de ataques por parte de los comerciantes. 
indígenas, como la construcción de caminos vecinales y aulas escolares. Mientras tanto, ante las presiones del capital privado, la intervención de BEMEX fue bastante restringida, mantuvo su presencia durante la década de los años sesenta, los comerciantes que a la vez eran productores de café seguían explotando la fuerza de trabajo de los campesinos sin tierra, compraban el café a los pequeños productores y al mismo tiempo prestaban dinero con intereses muy altos entre el 15 y $20 \%$ mensual, estos mecanismos de explotación les permitían incrementar sus ingresos y propiedades (Flores \& León, 1979).

4) Mayor Penetración del sector público (1970-1973) mediante el INMECAFE en las zonas cafetaleras, sin embargo, el impacto fue muy reducido ya que los sistemas productivos en las zonas cafetaleras no se modificaron, prevaleciendo el crédito amarrado como la base del poder y control por parte de los caciques regionales donde existía el sistema patrón-peón, además de que los asalariados estaban bajo el control privado.

5) Intensificación de la Penetración (1973-1976) cuyo objetivo era una mayor incursión del INMECAFE, organizando a los productores en Unidades Económicas de Producción y Comercialización (UEPC) y la expansión de una red para compras directas a los productores, para lo cual se facilita a los socios de la UEPC anticipos sobre sus futuras cosechas, ya que la mayoría de ellos no eran sujetos de crédito institucional. Con esta medida se redujeron las operaciones del crédito privado.

A partir de 1976, la actividad del INMECAFE se redujo, entre 1976 y 1986 no pudo comprar a los productores más allá de la quinta parte de su producción, se intensificaron las críticas y presiones por parte del sector privado porque el instituto había trastocado al capital financiero, alterando las reglas del mercado con los precios de garantía impuestos, con el sostenimiento de un precio mínimo para el aromático, canalizando asistencia técnica oficial, organizando a los campesinos y otorgando créditos a los campesinos. El instituto desaparece en 1989, mismo año en que la resolución de la Organización Internacional del Café (OIC) abandona el sistema de cuotas que permitía el control de la oferta mundial del grano y en su lugar el mercado se volvió el determinante fundamental para la actividad cafetalera (CEDRSSA, 2014).

Pese a las acciones emprendidas por este instituto, el resultado no fue halagüeño, ya que tanto factores internos de las regiones, como la crisis del café y del sector agropecuario nacional y procesos externos, incidieron de manera directa en la producción y comercialización del aromático. La venta del café ocupó un lugar importante, siendo líder en la generación de divisas hasta del año 1976. En 1966 la exportación del café representó 17\% de las ventas agrícolas hacia el exterior y llegó a 24\% en 1970; $28 \%$ en 1975 y 45\% en 1976. Este aumento fue resultado, en gran parte, de las condiciones del mercado internacional en donde el café fue, después del petróleo, el producto mexicano que más se exportó. En 1977 el aromático generó el $10 \%$ de las exportaciones de mercancías y más de la mitad del valor del sector agropecuario, proporción que fue disminuyendo, alcanzando para el año 1982, sólo el 2\% de las exportaciones (INECOL.EDU.MX, 2014).

La crisis del café en México tiene como referente la cancelación de acuerdos internacionales que regulaban la oferta, lo que provocó la salida al mercado de los excedentes y el desplome en los precios entre 1989 y 1993, a tal grado que no se cubría ni el costo de la pizca. Los pequeños y medianos cafeticultores empezaron a desertar, al principio buscaron otros ingresos para compensar las pérdidas, regalaban la cosecha a quien quisiera pizcar con el objetivo que los frutos que se quedaran no dañaran el cafetal o montaban la huerta en espera de mejores tiempos. Después malbarataron las plantaciones o las tumbaron y/o quemaron para introducir ganado alpinista o sembrar milpas de ladera, con rendimientos precarios. En consecuencia, como bucle recursivo se da el deterioro medio ambiental y social, debido a que el cambio desordenado de cultivos ocasiona deforestación, pérdida de suelos, menor rendimiento hídrico e incremento de plagas agrícolas por la reducción de aves migratorias que anidaban en las huertas (Bartra, 2003). Quienes han logrado sobrevivir son los productores organizados con la capacidad de colocar el aromático en nichos de mercado que pagan sobreprecios y los que se han especializado en el café orgánico, que ha colocado a México en el primer productor a nivel mundial. Hasta el año 2013, la situación de los cafeticultores de Huautla de Jiménez no era 
nada favorable, ya que años atrás ante las desventajas del mercado internacional y la crisis en el sector agropecuario, muchos abandonaron la tierra (Sánchez, 2013).

Como una medida para mitigar la pobreza de la población han llegado desde hace décadas, fondos de programas asistencialistas como el Programa Nacional de Solidaridad, el Programa Oportunidades y Cruzada Nacional contra el Hambre, operados desde la Secretaria de Desarrollo Social (SEDESOL, 1992) instrumentando una política de dar, que no ha propiciado de manera general la creatividad de las comunidades ni las capacidades autogestivas que faciliten el desarrollo de las comunidades. En la localidad, la opinión generalizada es que estos programas no han contribuido en el desarrollo productivo ya que, si bien es cierto han coadyuvado a elevar el nivel educativo, por otro lado, han propiciado mayor número de embarazos a temprana edad, pues "es más redituable tener hijos que cultivar una hectárea de café" (Rodríguez, 2011).

\section{VULNERABILIDAD TERRITORIAL}

La interacción de las condiciones propias del suelo, de las formas en que se han ubicado los asentamientos humanos, el deterioro medio ambiental del entorno y la confluencia de fenómenos naturales, han contribuido a generar condiciones de vulnerabilidad y por lo tanto a construir riesgo y peligro. El asentamiento humano de Huautla se ubicó, por razones históricas y de cosmovisión, en las partes altas de las laderas, en una zona qué por las condiciones del suelo y las lluvias constantes, es proclive a derrumbes, deslaves y desgajamiento de tierra:

"En el mes de septiembre tres dias de lluvias torrenciales destruyeron gran parte del camino carretero que comunica a Teotitlán, en la población el agua destruyó algunas calles sobre todo la principal, quedando incomunicadas varias zonas de la ciudad. En pocas palabras, el pueblo quedó aislado del exterior y dentro aislado en dos y tres tramos, debido en gran parte a la topografía propia del lugar. En la casa que rentamos para nuestras oficinas se tuvo que abrir un desagüe nuevo, ya que corrientes de agua aparecieron intempestivamente, dañando la tubería de agua potable y socavando los cimientos de la casa, hundiéndose las habitaciones centrales en forma aparatosa con rajaduras en las paredes y la losa del piso. Los trabajos los tuvimos que hacer nosotros sin la ayuda del pueblo, ya que no era posible pedirles cooperación en esos momentos, pues se encontraban ocupados levantando derrumbes en el tramo que les corresponde del camino carretero que conduce a Teotitlán...” (Incháustegui, 1960-1969).

La sierra donde está ubicado el asentamiento presenta elevaciones que oscilan entre los 1,000 y $2,400 \mathrm{msnm}$, entre los 1,500 y 2,000 msnm se ubica la mayor parte de la población sobre pendientes que van desde $<8.5^{\circ}$ hasta $>26.7^{\circ}$, lo que puede significar situaciones de peligro para los asentamientos humanos ubicados en las clasificadas como moderadas y no aptas para la urbanización. Aunado a la inestabilidad del terreno natural, característica de algunas zonas montañosas donde la superficie del mismo presenta diversos grados de inclinación, la inestabilidad -definida como la pérdida de capacidad del terreno natural para auto sustentarse- deriva en reacomodos y colapsos del mismo, originando deslizamientos (Castillo, 2013). El peligro a deslizamientos, considerando factores geológicos, pendientes, precipitaciones, aceleración sísmica y la forma e intensidad en el uso del suelo que hasta ahora se ha presentado en la construcción de la ciudad, podrían acelerar o generar un número mayor de deslizamientos, con consecuencias desastrosas para la población (H. Ayuntamiento de Huautla de Jiménez, 2012) (ver fotografías 1 y 2). 


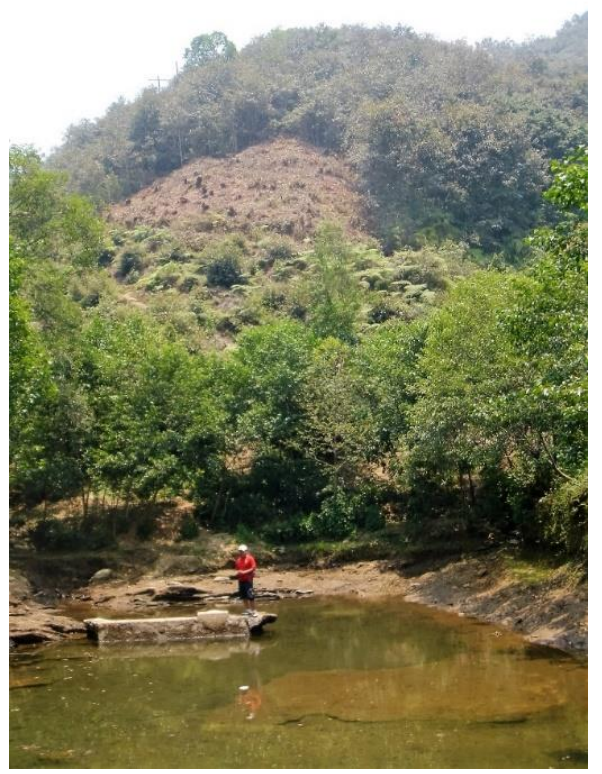

Foto 1. Ladera deforestada sobre área de almacenamiento y bombeo de agua a la red que provoca desgajamiento de tierra, azolvando esta área y generando desabasto del vital líquido (López, 2011).

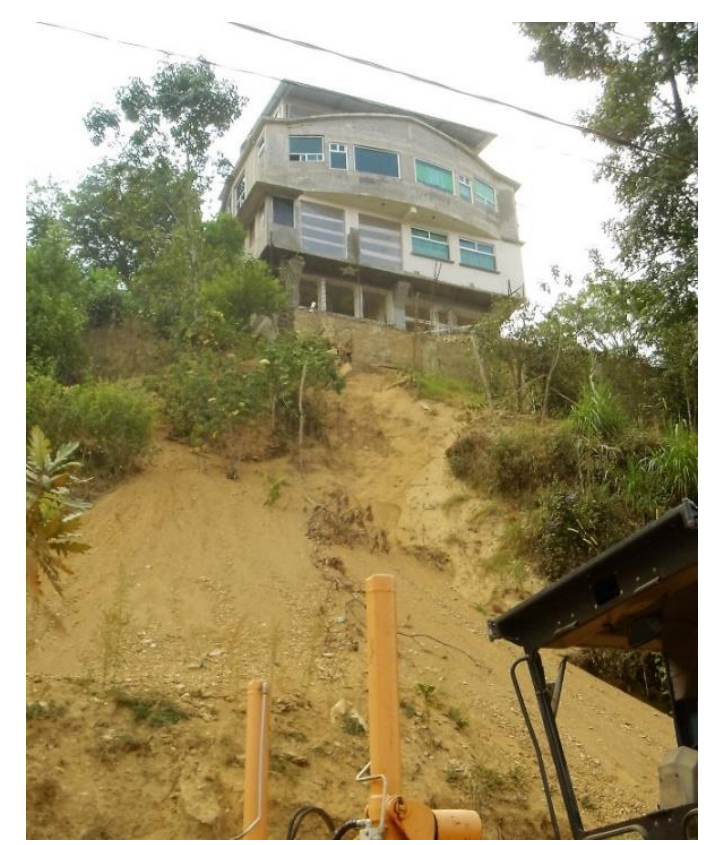

Foto 3. Vivienda ubicada sobre ladera que ya presenta desgajamiento (López, 2011).

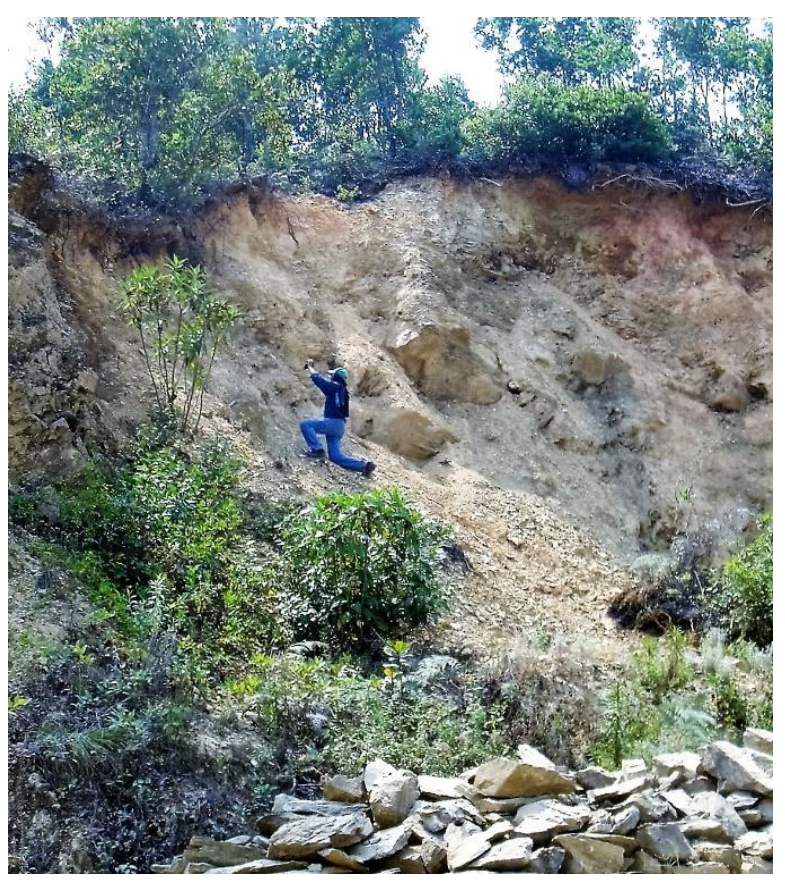

Foto 2. Desgajamiento de ladera (López, 2011).

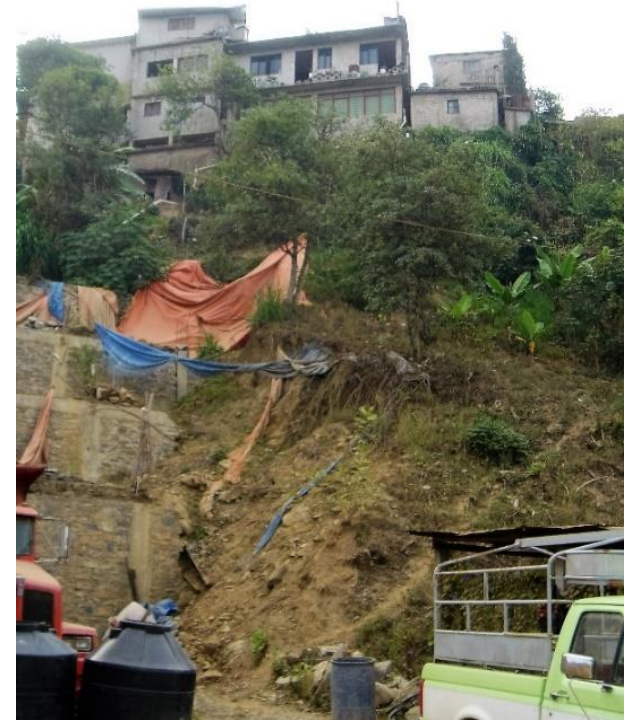

Foto 4. Viviendas ubicadas sobre ladera en proceso de desgajamiento (López, 2011).

El asentamiento humano y su crecimiento, pasando de 101.25 has a 362.09 en el período 19852011, incluyendo zonas consolidadas y asentamientos dispersos, desde su origen ha sacrificado zonas de bosque mesófilo de montaña, introduciendo zonas de cultivo y pastizales. Aún se cuenta con masas vegetales que es necesario conservar, porque además de contribuir a mitigar los deslizamientos, son las únicas fuentes de captación de agua para el consumo de la población. Sin embargo, el patrón de crecimiento observado hasta ahora se caracteriza por densificación de la parte central, asentamientos 
dispersos en la periferia, mismos que se densifican con el paso del tiempo, generando nuevas periferias, lo que pone en peligro a los ecosistemas naturales circundantes, el abastecimiento de agua y al asentamiento humano por deslizamientos (ver fotografías 3 y 4).

La intensidad en el uso del suelo obedece a que las viviendas, construidas sobre las fuertes pendientes topográficas, aprovechan la superficie construida con anterioridad para levantar hasta cuatro niveles de altura, sin que en la mayoría de las veces medie un cálculo estructural ni de mecánica de suelos que indique la capacidad de carga máxima del mismo. Al año 2012 no existía en la comunidad un reglamento de construcciones ni normativa en este sentido. Además, por las fuertes pendientes del suelo, las instalaciones hidráulicas y de drenaje se han realizado superficialmente, de manera individual y por adhesión de tubería, esto es, se van añadiendo tramos conforme se va necesitando, pero sin la utilización de un procedimiento técnico adecuado, generando fugas de agua constantes que contribuyen al reblandecimiento del suelo, que con la sobrecarga por el peso de las construcciones y la vibración al pasar de autos, camionetas y vehículos pesados, provocan desgajamientos y derrumbes de tierra. Los drenajes a cielo abierto vertidos en las cañadas y brechas que atraviesan la comunidad, generan olores desagradables, contaminación del suelo, aire y agua que es filtrada por el subsuelo en las partes bajas y es consumida por la población (H. Ayuntamiento de Huautla de Jiménez, 2012).

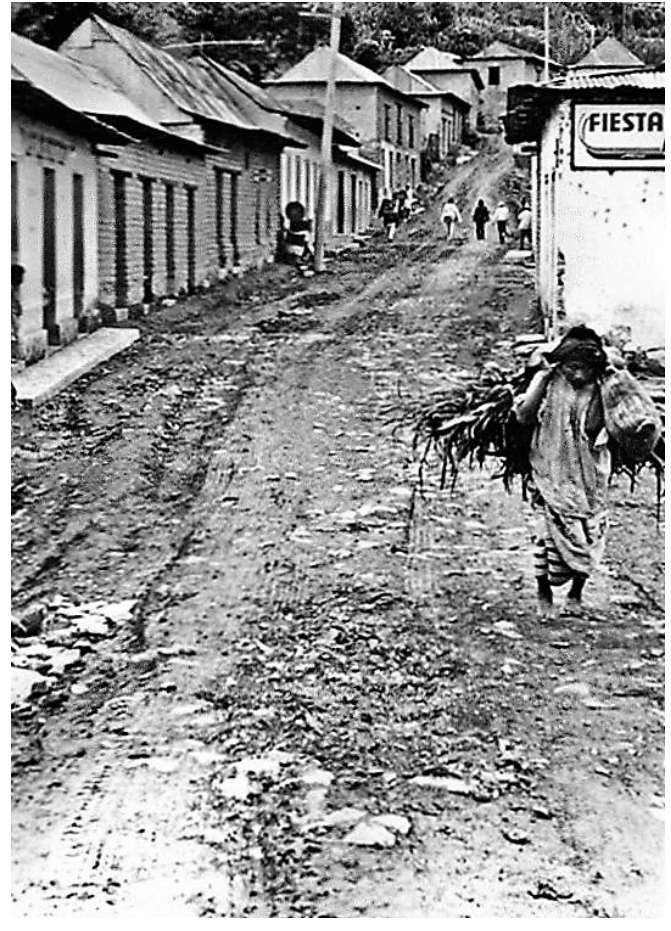

Foto 5. Calle del centro de la comunidad década de los años 60 (Fernández, 2011).

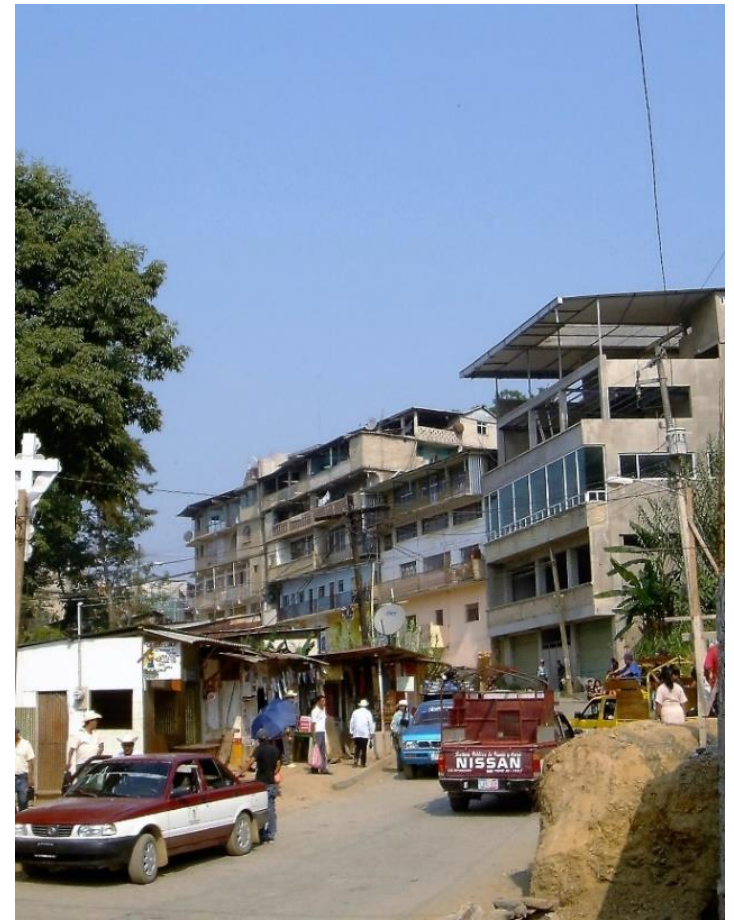

Foto 6. Calle principal del centro de la comunidad, en donde se puede observar la diversidad de materiales y alturas (López, 2011).

En cuanto a la imagen urbana de la comunidad, la introducción desde la década de los años setenta de materiales, productos, técnicas, equipos y herramientas para la construcción no propias de la región, así como la influencia de formas arquitectónicas provenientes de los lugares donde los familiares y/o propietarios de los inmuebles trabajan ${ }^{23}$, visitan o ven por los medios de comunicación, han impreso a las construcciones de Huautla características ajenas y discordantes entre sí y con el contexto urbanoarquitectónico, y por supuesto con la aptitud y capacidad de carga natural del suelo (ver fotografías 5 y 6). En los perfiles urbanos se pueden apreciar viviendas de varios niveles de altura, con diversidad de materiales, colores, formas y proporciones, mismos que como bucle recursivo se instalan en la localidad y sirven de referente para inspirar futuras construcciones y así sucesivamente (López et al., 2015).

23 Estado de México, Puebla, el Distrito Federal, Veracruz, Oaxaca, inclusive de los Estados Unidos. 
Estos factores, al igual que los socioeconómicos, forman parte de vulnerabilidades acumuladas históricamente en la comunidad y que aunado a la escasez de los hongos alucinógenos por la afectación de los bosques y los ecosistemas, la disminución de las prácticas de medicina tradicional, la desvalorización de sus tradiciones y costumbres, la pérdida paulatina del tequio como una forma de solidaridad y cooperación comunitaria, así como de la lengua indígena, colocan a Huautla de Jiménez, Oaxaca, a decir de algunos de sus habitantes, en una comunidad vulnerable culturalmente hablando (Rodríguez, 2011).

\section{CONCLUSIONES}

El aproximarnos a entender la vulnerabilidad socio territorial de la ciudad indígena Huautla de Jiménez, Oaxaca, nos llevó a comprender las transformaciones y los procesos que históricamente intervinieron en ellas. La alta marginación en la que viven cientos de mazatecos, en una zona productora de café, cultivo importante en la generación de divisas para México, tiene su origen en la pérdida de las formas de administración y organización indígena tras la llegada de los españoles, en el despojo de tierras comunitarias en favor de hacendados y finqueros -avalados por las leyes que buscaban "blanquear al país" eliminando al indio del contexto-, así como en las acciones de política pública "indigenista" que a partir de los años cuarenta del siglo XX se encaminaron a integrar a las sociedades indígenas a la nación, siendo relevantes en la zona de estudio el papel del INI y el INMECAFE, facilitando la entrada del sector público y privado en regiones indígenas.

Esta integración supondría mejora social en las comunidades, sin embargo, las dialógicas de los actores involucrados, por un lado, latifundistas, caciques y comerciantes, y por el otro pequeños productores y jornaleros, pusieron de manifiesto que quienes ostentan el poder político y económico imponen acciones y formas coercitivas, en favor de los primeros, sin considerar la necesidad de elevar el nivel socio económico y la calidad de vida de los pequeños productores y jornaleros. Esto desató una pugna constante de intereses, cuyas manifestaciones se dejaron sentir con el asesinato del líder de los cafetaleros en el año de 1962 y en las constantes amenazas y represiones sobre los pequeños productores.

La vulnerabilidad socio económica como bucle recursivo, ha perpetuado el atraso que vive la población, sentando y reproduciendo la situación de dominación y explotación. No se puede soslayar que esto es una representación hologramática de procesos externos, como la crisis general del agro mexicano y del café. Tampoco se puede negar que desde la década de los años ochenta, con los tratados internacionales y la entrada del neoliberalismo económico, somos más dependientes y más vulnerables a lo que suceda, por ejemplo con el precio del café a nivel internacional y porque no decirlo, también a los precios del petróleo, producto en que está fundamentada parte importante de la economía mexicana.

Pese a la implementación de una serie de programas federales operados por la SEDESOL en la región para abatir los niveles de pobreza, desde la década de los años noventa, tampoco se han obtenido logros, ya que no han generado capacidades autogestivas para la producción entre los miembros de la comunidad, por las formas en que han sido implementados, tendientes a institucionalizar el paternalismo y a tener un control político sobre la población de las regiones. Muchos de los programas han sido operados mediante el seguimiento de manuales estandarizados, no diseñados de acuerdo a las realidades socio económicas y culturales, ni de los actores involucrados, generándose una especie de cultura del dar y recibir, que, aunado a las divisiones operadas con la entrada de los partidos políticos, no han permitido fortalecer, al menos en Huautla la capacidad de organización comunitaria. Por el contrario, el consejo de ancianos, el tequio y las faenas se están perdiendo, junto con otras expresiones culturales y organizaciones sociales que formaban históricamente parte de su identidad y fortaleza como comunidad, debilitando su capacidad de autogestión política y económica.

No todo está perdido, en los recorridos realizados en la localidad, pobladores expresaron abiertamente su sentir en cuanto a las problemáticas socio-territoriales que padecen y su preocupación por implementar acciones comunitarias participativas, en torno a estas, que propicien entre otros aspectos: 
a) Disminuir los índices de analfabetismo, deserción escolar, embarazos a temprana edad, con la participación de los jubilados del magisterio.

b) Aminorar la violencia intrafamiliar, desnutrición infantil y abandono de infantes.

c) Frenar la pérdida de la lengua indígena entre los niños y adolescentes, con la colaboración de hablantes del mazateco.

d) Fortalecer las tradiciones, cosmovisión y la medicina tradicional, institucionalizándolos como prácticas culturales activas.

e) Crear acuerdos sobre los lugares y la forma que se puede construir para no seguir deteriorando el medio ambiente.

f) Reforzar las capacidades productivas locales e implementar cadenas de comercialización.

g) Aprovechar los entornos naturales para generar actividades de bajo impacto ambiental que fortalezcan la economía local.

Las soluciones no pueden llegar como una imposición externa, ya que son ellos, los huautlecos con base en sus fortalezas, los únicos que pueden recuperar, a partir de los lazos interfamiliares, su capacidad de auto organización, auto gestión y solidaridad comunitaria, para hacerle frente a la vulnerabilidad socio territorial que padecen.

\section{BIBLIOGRAFÍA}

Bartra A (2003). Cosechas de Ira: Saldos de la contrarreforma agraria (1ª ed.). México DF, México: ITACA-Instituto Maya, $140 \mathrm{pp}$

Beltrão FJ, Monteiro de Brito JC, Itziar Gómez F, Pajares E, Paredes F, Zúñiga Y (2014). dhes. Red de Derechos Humanos y Educación Superior. Manual de Derechos Humanos de Grupos Vulnerables. Disponible en: https://www.upf.edu/dhes-alfa/materiales/docs/DHGV_Manual.pdf, $478 \mathrm{pp}$

Boege E (1992). Contradicciones en la identidad étnica mazateca: consruyendo el objeto de estudio. Nueva Antropología XIII(43):61-81. Disponible en http://historico.juridicas.unam.mx/ publica/librev/rev/nuant/cont/43/pr/pr7.pdf

Boege E (2008). El patrimonio biocultural de los pueblos indigenas de México. México DF, México: INAH-CDI. Disponible en http://www.cdi.gob.mx/biodiversidad/ biodiversidad_0_preliminares_1-31_eckart_boege.pdf, 31 pp

Castillo J (2013). Zonas aptas para la urbanización en Huautla de Jiménez, Oaxaca. (LV López V, entrevistador) Puebla, Puebla, México. Recuperado el 12 de marzo de 2016

Castro S (2014). México el país de los desplazados: 2 millones por desastres, más de millón y medio por violencia. En: Zacatecas 3.0, el 19 de septiembre de 2014. Disponibles en http://zacatecastrespuntocero.com/mexico-el-pais-de-los-desplazados-2-millones-por-desastresmas-de-millon-y-medio-por-violencia/

CDI (2012). Instituto Nacional Indígenista y Comisión para el Desarrollo de los Pueblos Indígenas 1948-2012 (1 ${ }^{\mathrm{a}}$ ed.). México DF, México: Comisión para el Desarrollo de las Pueblos Indígenas. Recuperado el 15 de enero de 2016

CEDRSSA (2014). Producción y mercado de café en el mundo y en México. México: Centro de Estudios para el Desarrollo Rural Sustentable y la Soberanía Alimentaria. Disponible en https://www.cedrssa.gob.mx/includes/asp/download.asp?iddocumento=2756\&idurl=4576, $18 \mathrm{pp}$

CONEVAL (2010). Informe anual sobre la situación de pobreza y rezago social. Huautla de Jiménez, Oaxaca. SEDESOL-CONEVAL. SEDESOL-CONEVAL. Disponible en https://www.gob.mx/cms/uploads/attachment/file/34376/Oaxaca_041.pdf, 2 pp

CONEVAL (2015). Medición de la pobreza en México. México: Consejo Nacional de Evaluación de la Política de Desarrollo Social. Disponible en http://www.coneval.org.mx/Medicion/MP/ Paginas/Pobreza_2014.aspx. Recuperado el 11 de febrero de 2016 
Cuervo L (2012). Ética territorial Ética y política económica. Discusión de sus relaciones fundamentales a la luz de las políticas de desarrollo territorial. Instituto Latinoamericano y del Caribe de Planificación Económica y Social, serie desarrollo territorial. Disponible en http://repositorio.cepal.org/bitstream/handle/11362/7245/1/S1200547_es.pdf

Fernández E (2011). Huautla, su historia. (LV López V, entrevistador) Huautla de Jiménez, Oaxaca, México. Recuperado el 10 de enero de 2016

Flores M, León A (1979). La política del Inmecafé y la Sierra Mazateca (1973-1976). Revista Comercio Exterior 29(7):767-778

García R (2006). Sistemas complejos. Conceptos, método y fundamentación epistemológica de una investigación interdisciplinaria ( $1^{\mathrm{a}}$ ed.). Barcelona, España: Gedisa, pp. 19-35

Goujon G (2009). Culturas exóticas: análisis crítico de relatos etnográficos. Tesis de pregrado, Facultad de Antropología, Universidad Veracruzana, $116 \mathrm{pp}$. Disponible en https://www.academia.edu/3192158/CULTURAS_EX\%C3\%93TICAS

Gutiérrez R (2016). 200 mil mexicanos perdieron su hogar a causa de las presas y la nueva ley viene aún peor. Disponible en http://www.agua.org.mx/noticias/not-nacionales/38906-200-milmexicanos-perdieron-ya-su-hogar-a-causa-de-las-presas-y-la-nueva-ley-viene-aun-peor. Recuperado el 30 de marzo de 2016

H. Ayuntamiento de Huautla de Jiménez (2012). Programa Municipal de Desarrollo Urbano Sustentable de Huautla de Jimenez, Oaxaca. Huautla de Jiménez: Gobierno del Municipio de Huautla. Recuperado el 12 de marzo de 2016

Hussein R (2015). México: Una ola de continuas violaciones de derechos humanos. Naciones Unidas, Derechos Humanos. Disponible en http://www.ohchr.org/SP/NewsEvents/Pages/

HCMexicoVisit.aspx. Recuperado el 12 de febrero de 2016

IFRC.ORG (2014). ¿Que es la vulnerabilidad? Federación Internacional de Sociedades de la Cruz Roja y de la Media Luna Roja. Disponible en http://www.ifrc.org/es/introduccion/disastermanagement/sobre-desastres/que-es-un-desastre/que-es-la-vulnerabilidad/. Recuperado el 3 de febrero de 2016

Incháustegui C (1960-1969). Informes mensuales. Reportes y manuscritos del INI, Huautla de Jiménez. Recuperado el 12 de agosto de 2013

INECOL.EDU.MX (2014). Antecedentes del café en México. INECOL. Disponible en http://www3.inecol.edu.mx/biocafe/ARCHIVOS/libros/qbh/2-Antecedentes.pdf, 14 pp. Recuperado el 2 de marzo de 2016

INEGI (2010). Censo de Población y Vivienda. Aguascalientes: Instituto Nacional de Estadística y Geografía. Disponible en http://www.inegi.org.mx/sistemas/consulta_resultados/ iter2010.aspx?c=27329\&s=est. Recuperado el 21 de enero de 2016

Instituto Méxicano de Competitividad (2014). Medición de la pobreza en México 2014 vía CONEVAL. Informe basado en indicadores publicados en la Encuesta Nacional de Ingresos y Gastos de los Hogares del Instituto Nacional de Estadística y Geografía, México DF, México. Disponible en http://imco.org.mx/banner_es/medicion-de-la-pobreza-en-mexico-2014-viaconeval/. Recuperado el 12 de enero de 2016

Instituto Nacional Indigenísta (1994). Mazatecos, pueblos indígenas de México. México: INI. Recuperado el 08 de febrero de 2016

Korsbaek L, Samano M (2007). El indigenismo en México, antecedentes y actualidad. Ra Xinhai, 1(3):195-204

La Jornada (2015). Siria, Irak y México con más muertos por conflictos en 2014, reporta IISS. La Jornada Mundo. Disponible en http://www.jornada.unam.mx/2015/05/21/mundo/021n1mun. Recuperado el 3 de marzo de 2016

López R (1992). Problemas metropolitanos y desarrollo regional. México: UAM-Azcapotzalco. pp. $97-112$ 
López R (2010). La megalopolis de la región centro de México: Sistema complejo. En: Eibenshutz Hartman R (coord.). La zona metropolitana del Valle de México: Los retos de la megalópolis ( ${ }^{\mathrm{a}}$ ed.), pp. 59-90. México DF, México: Universidad Autónoma Metropolitana

López L, López A, Cabrera V (2015). Patrimonio y territorio en la Sierra de Huautla de Jiménez, Oaxaca (1 ${ }^{\text {a }}$ ed.). Puebla: CIPAC A.C. Recuperado el 10 de marzo de 2016

Luna R (2007). Mazatecos. Pueblos indígenas del México contemporáneo. México: Comisión Nacional para el Desarrollo de los Pueblos Indígenas. Disponible en https://www.gob.mx/ cms/uploads/attachment/file/11676/mazatecos.pdf, 58 pp. Recuperado el 12 de enero de 2016

Maldonado G, Cóccaro JM (2011). Esquema teórico para el estudio de la vulnerabilidad socioterritorial a inundaciones en ambitos rurales. Revista Geográfica Venezolana 52(2):81-100

Morin E (2000). Introducción al pensamiento complejo ( $1^{\mathrm{a}}$ ed., $3^{\mathrm{a}}$ reimpresión). Barcelona, España: Gedisa, $167 \mathrm{pp}$

Nolasco M (1985). Café y sociedad en México (1 ${ }^{\mathrm{a}}$ ed.). México DF, México: Centro de Ecodesarrollo, $454 \mathrm{pp}$

Quintanar M, Maldonado B (1999). La gente de nuestra lengua. El grupo etnolinguistico chjota enna (mazatecos). En: Barabas AM, Bartholome MA (coords.) Configuraciones étnicas en Oaxaca. Perspectivas etnográficas para autonomías, Vol. II, pp. 9-54. México DF, México: Instituto Nacional Indígenista

Rodríguez A (2011). Pérdida de tradiciones y costumbres indígenas en Huautla. (LV López V, entrevistador), Huautla de Jiménez, Oaxaca, México. Recuperado el 27 de febrero de 2016

Rojo J (2014). Chinantecos desplazados por la presa Cerro de Oro, en Oaxaca. El Cotidiano (183):4350. Disponible en http://www.redalyc.org/pdf/325/32529943006.pdf

Ruiz A, Campechano B (2006). Pobreza y desigualdad social en Oaxaca 1990-2000: una perspectiva regional. Revista Observatorio de la Economía Latinomericana (59). Málaga, España: Servicios Académicos Intercontinentales S.L. con el apoyo de Grupo EUMED.NET

Salazar LM (2015). Existen en México 700 mil desplazados por la violencia. SDPNoticias.com. Disponible en http://www.sdpnoticias.com/nacional/2015/09/10/existen-en-mexico-700-mildesplazados-por-la-violencia. Recuperado el 26 de febrero de 2016

Sánchez R (2013). La transformación de INI a CDI. (LV López V, entrevistador), San Pedro, Cholula, México. Recuperado el 18 de Febrero de 2016

SEDESOL (2015). Catálogo de localidades, sistema de apoyo para la planeación. Dirección General Adjunta de Microrregiones, Unidad de Microrregiones. México: Secretaria de Desarrollo Social. Disponible en http://www.microrregiones.gob.mx/catloc/LocdeMun.aspx? tipo $=$ clave $\&$ campo $=$ loc\&ent $=20 \&$ mun $=041$. Recuperado el 23 de enero de 2016

Traffano D (2012). Historias e imágenes del siglo XX: el Estado de Oaxaca. (Nahón A, Ed.) Revista Cuadernos del Sur 17(32):9-28

Verdugo W (2003). Magos de América. El Galeón.com. Disponible en http://magosdeamerica.galeon.com/. Recuperado el 14 de enero de 2016 